\title{
Effect of using previously banked samples on SNP genotyping of livestock animals
}

A.A. Zwane ${ }^{1,2 \#, \text { K.T.E. Makua }}{ }^{2}$, M.L. Makgahlela², A. Maiwashe ${ }^{1,3}$

${ }^{1}$ Department of Animal Breeding and Genetics, ARC-Animal Production, Private Bag x2, Irene, 0062, South Africa, ${ }^{2}$ Department of Animal Science, Tshwane University of Technology, Private Bag X 680, Pretoria 0001, ${ }^{3}$ Department of Animal, Wildlife and Grassland Sciences, University of the Free State, Bloemfontein 9300, South Africa.

Introduction: Genome-wide single nucleotide polymorphisms (SNPs) have become increasingly popular in population genetic studies. Genetic sampling methods for hair, tissue, and blood samples among others, has increased the scope and efficiency of genomic studies in livestock population, including cattle. Most previously banked samples are unsuitable for DNA analyses due to their extensive degradation due to poor sampling and storage conditions (Der Sarkissian et al., 2015). Environmental exposure to moisture and ultraviolet radiation can degrade DNA in biological samples, whereas cool and dry conditions are known to minimize degradation (Stetz et al., 2015) Sequences of DNA can be easily broken as DNA is a fragile molecule (Lindahl 1993) which in turn can affect SNP genotyping. As genotyping is still expensive in most developing countries, lower call rate and failed genotyping can be a challenge since repeated genotyping is costly. Therefore, limiting exposure to DNA degradation on collected samples is important component for genomic study design.

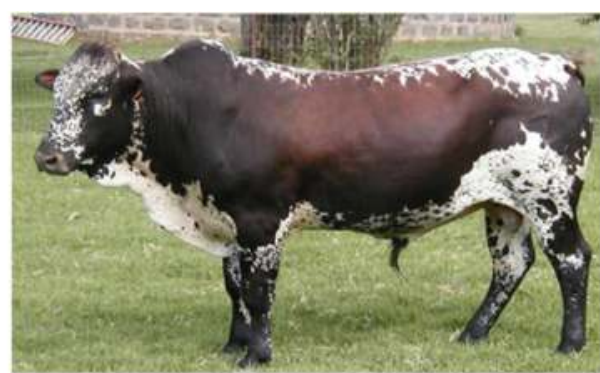

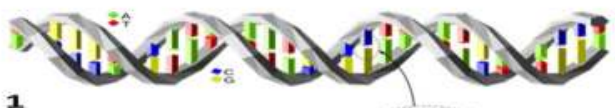

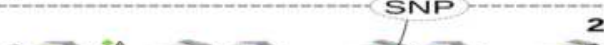
Did (1)
Aim and objectives: To determine the effect of using previously banked samples on SNP genotyping of cattle. Quantify the extracted DNA to check the DNA quality. Genotyping of hair samples previously banked. Determine the genotyping call rate and missing genotypes.

\section{0 (10}

Materials and Methods: Hair samples were collected from Afrikaner $(n=24)$, Drakensberger $(n=24)$ and Nguni $(n=24)$ Genomic DNA was extracted using an optimized Phenol-Chloroform protocol for hair samples. DNA was quantified using Nanodrop 2000c spectrophotometer (Thermo Scientific) and verified using Qubit ${ }^{\circledR} 2.0$ Fluorometer. Quantified DNA was prepared for genotyping at ARC-Biotechnology Platform using Illumina BovineSNP50 and $150 \mathrm{~K}$ assay. Genotypes were analysed using PLINK (Purcell et al., 2007).

Results

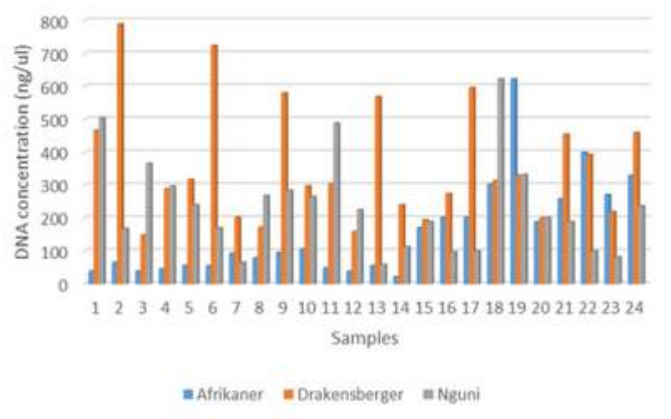

Figure 1: DNA quantification of samples as measured by the Qubit $₫ 2.0$ Fluorometer

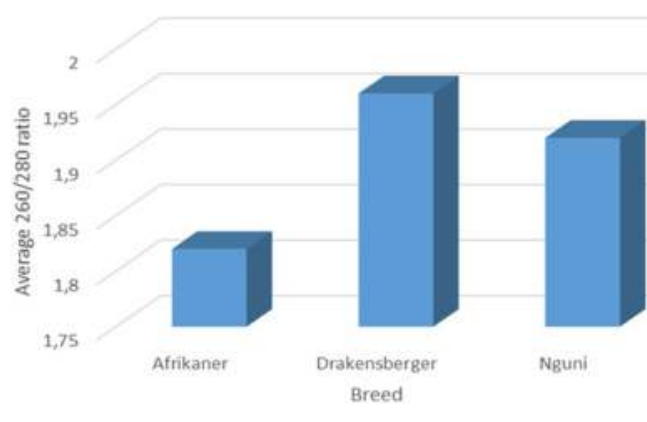

Figure 2: Average DNA quality for all the samples

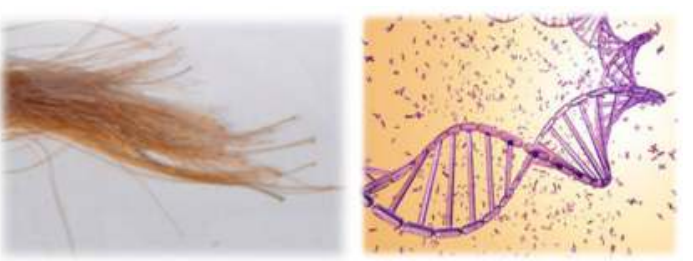

Table 1: Samples genotyping using Illumina BovineSNP50 and 150K assays the BovineSNP50 and 150K was successfu with the average genotyping call rate of $97 \%$. The lowest call rate was observed in Afrikaner (95\%). Afrikaner had a large number of samples that failed genotyping and this could be due to the quality of the hair samples that were compromised during and after the collection, including collecting hair without roots. Drakensberger and Nguni samples were least affected. The total number of SNPs left after filtering shows that there are number of SNPs that are lost during genotyping, and this could be because of the nature of assay used, and the effect of the assay design that didn't consider SNPs from the local breeds. Therefore standardized optimised protocols are needed to ensure the quality of DNA for genomics applications.

\begin{tabular}{|c|c|c|c|c|c|c|c|}
\hline Breed & $\begin{array}{l}\text { Total no. } \\
\text { of } \\
\text { samples } \\
\text { genotyped }\end{array}$ & $\begin{array}{l}\text { Samples } \\
\text { successfully } \\
\text { genotyped }\end{array}$ & $\begin{array}{l}\text { Samples } \\
\text { that failed } \\
\text { genotyping }\end{array}$ & $\begin{array}{l}\text { Samples } \\
\text { with } \\
\text { missing } \\
\text { genotypes }\end{array}$ & $\begin{array}{r}\text { Total } \\
\text { Number of } \\
\text { SNPs } \\
\text { genotyped }\end{array}$ & $\begin{array}{r}\text { Total SNP } \\
\text { call rate }\end{array}$ & $\begin{array}{r}\text { Total } \\
\text { number of } \\
\text { SNPs after } \\
\text { QC }\end{array}$ \\
\hline Afrikaner & 24 & 14 & 10 & 1 & 141716 & 0,95 & 89860 \\
\hline Drakensberger & 24 & 23 & 1 & 0 & 141716 & 0,98 & 117755 \\
\hline Nguni & 24 & 24 & 0 & 2 & 54609 & 0,98 & 39847 \\
\hline Total & 72 & 61 & 11 & 3 & 338041 & 0,97 & 247462 \\
\hline & & & & & & ric.za & \\
\hline
\end{tabular}

